\title{
Histórias cruzadas nas ruas do Rio de Janeiro
}

\section{Crossed Stories on the Streets of Rio de Janeiro}

\section{Histoires croisées dans les rues de Rio de Janeiro}

\begin{tabular}{l} 
Luciano Vinhosa * \\
\hline http://dx.doi.org/10.22409/poiesis. 1931.61-80
\end{tabular}

RESUMO: Inspirando-me nos escravos de ganhos observados por Debret no início do século XIX, traço com este ensaio um paralelo entre as transformações urbanas por que passou o Rio de Janeiro e a persistência de uma sub-cidade anacrônica em meio à ordem modernizadora e excludente. A turba emergente de vendedores ambulantes, forjando uma outra cidade superficial, movediça e oficiosa, gera uma mancha negra e efêmera que se superpõe diariamente ao desenho fixo da carta oficial. A reflexão está motivada na realização de um trabalho artístico que mapeia nos dias de hoje algumas dessas pequenas profissões marginalizadas em analogia àquelas que Debret registrou no passado.

PALAVRAS-CHAVE: cidade; outras cartografias; pequenas profissões

\footnotetext{
" Luciano Vinhosa é artista e professor do Departamento de Arte e do Programa de Pós-Graduação em Estudos Contemporâneos das Artes da Universidade Federal Fluminense. Doutor em Estudos e Práticas Artísticas pela Université du Québec à Montréal. Mestre em Artes Visuais pela Universidade Federal do Rio de Janeiro. Graduado em Arquitetura e Urbanismo pela Universidade Federal Fluminense. É Bolsista de Produtividade do CNPq. E-mail: luciano.vinhosa@gmail.com
} 
ABSTRACT: Inspired by the earnings slaves observed by Debret at the beginning of the nineteenth century, I draw with this essay a parallel between the urban transformations in Rio de Janeiro and the persistence of an anachronistic sub-city amid the modernizing and excluding order. The emerging mob of street vendors, forging another shallow, shifting and unofficial city, generates a black and ephemeral stain that daily overlaps the fixed design of the official letter. The reflection is motivated in the accomplishment of an artistic work that maps in the present day some of these small professions marginalized in analogy to those that Debret recorded in the past.

KEYWORDS: city; other cartographies; small professions

SUMMAIRE: En attention aux escravos de ganho prises par Debret au débout du $\mathrm{XIX}^{\text {ème}}$, cet essai mène un parallèle entre les transformations urbaines que la ville du Rio de Janeiro a subi et la persistance d'une sous-ville anachronique qui a résisté à la modernisation imposée par l'ordre hégémonique. La turbe émergeant de vendeurs itinérants forge sur la ville officielle une autre superficielle et mouvante. Une tâche noire en superposition à la carte urbaine officielle. Cette réflexion est motivée par la réalisation d'un travail artistique le quel nous présente une cartographie de ces petites professions marginalisées en analogie à celles que Debret a enregistré autrefois.

MOTS-CLES: ville; autres cartographies; petites professions

Como citar: VINHOSA, Luciano. Histórias cruzadas nas ruas do Rio de Janeiro. Poiésis, Niterói, v. 19, n. 31, p. 61-80, jan./jun. 2018. doi: http://dx.doi.org/10.22409/poiesis.1931.61-80

Poiésis, Niterói, v. 19, n. 31, jan./jun. 2018. 


\section{Histórias cruzadas nas ruas do Rio de Janeiro}

\section{Por uma etnografia das ruas}

O Rio de Janeiro de Debret, Coleção Castro Maya, esteve em cartaz no Centro Cultural dos Correios no Rio de Janeiro de 4 de março a 3 de maio de 2015. A exposição, reunindo gravuras, aquarelas e desenhos do artista francês, nos trouxe de volta as ruas do início do século XIX, quando esta cidade se preparava, então, para ser a metrópole de hoje. Por outro lado, fez-me refletir sobre o quanto ainda podemos perceber dos traços da sociedade daqueles tempos no Rio de Janeiro de nossos dias.

A partir dessa constatação inicial, comecei a desenvolver um trabalho artístico associando alguns daqueles de Debret, em que o artista registra certos serviços de escravos de ganho, de aluguel ou de negros forros às imagens fotográficas de trabalhadores informais recolhidas por mim diretamente nas ruas do Rio de Janeiro. O objetivo deste trabalho é menos o de constatar a persistência hoje das profissões precárias transcorridos duzentos anos, do que o de trazer à tona, através de uma cartografia outra, uma cidade, dentre tantas outras oficiosas, se desenvolvendo oportunamente sobre a tessitura daquela oficial. Uma sobreforma efêmera e circunstancial existindo nas horas do dia, em certos dias 


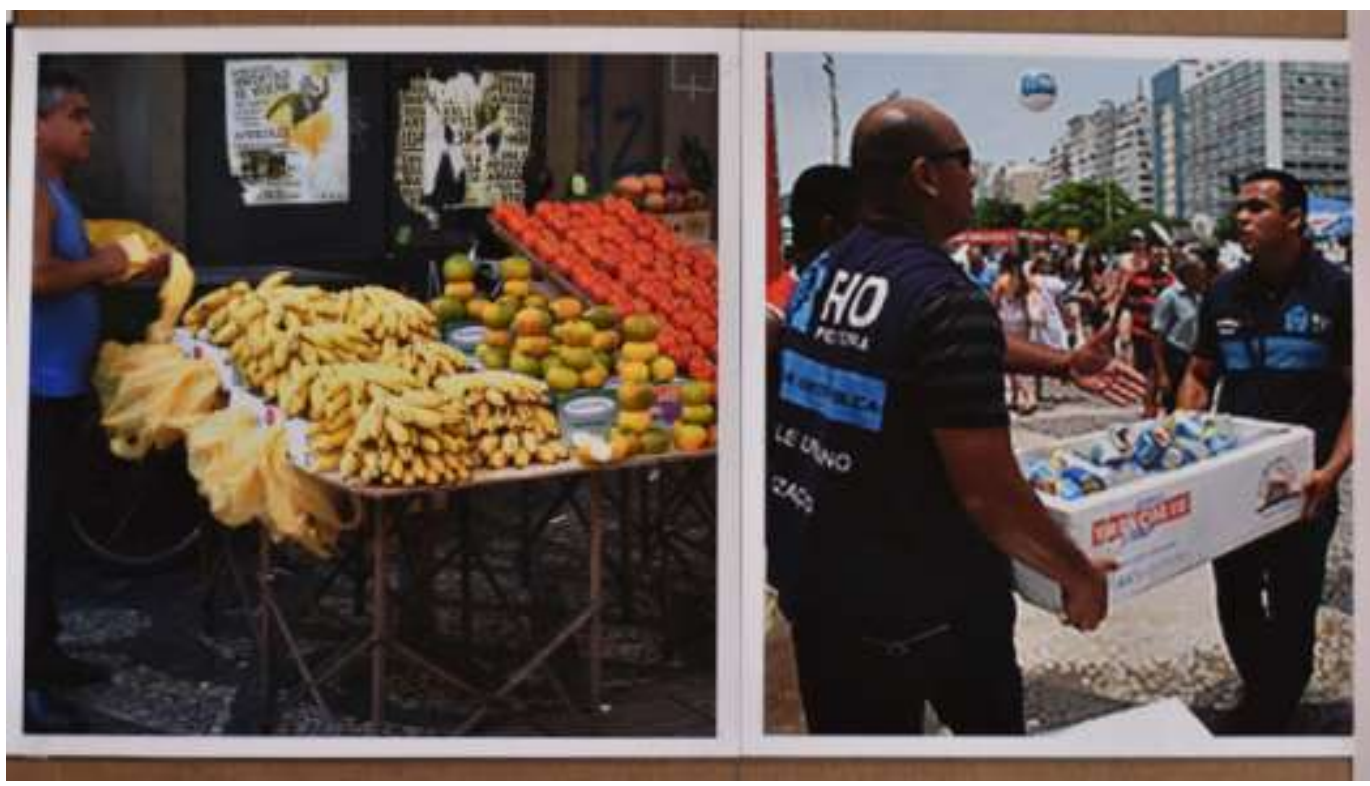

Fig. 1 - Luciano Vinhosa, Histórias cruzadas (detalhe), 2018.

montagem / colagem/ desenho

Poiésis, Niterói, v. 19, n. 31, jan./jun. 2018. 
da semana. Uma sub-cidade suja e barulhenta que se aloja nas dobras da outra MaraviIhosa vendida para os turistas. Um afluxo sazonal de excluídos que se servem de táticas de inteligência, ao mesmo tempo em que enaltecem a vida urbana com seu colorido e alegre algazarra.

Os homens e as mulheres que a produzem, todos eles pobres e quase todos pretos, sem acesso aos bens de consumo e às tecnologias do mundo moderno, movem-se, no dizer de Milton Santos, em uma "temporalidade outra", própria do lugar. Por este motivo escapam, ainda que involuntariamente, dos processos generalizados da globalização. Esses personagens, por necessidade e bravura, reinventam constantemente mecanismos de sobrevivência e resistem àqueles que Ihes querem extirpar com violência da paisagem. Como vira-latas, vivem das oportunidades e às ruas sempre retornam para retirar seu ganha-pão quando as sentinelas da repressão se descuidam. São eles que, levando à população diariamente seus pequenos serviços e produtos, atendem as demandas eventuais de transeuntes e moradores, fortalecendo os elos sociais e as redes de boa vizinhança. Sua presença nos logradouros aumenta a sensação de segurança do cidadão muito mais do qualquer força policial armada. (Fig. 2)

\section{O Rio de Debret}

Naquela época, com uma população em torno de 150.000 almas, o Rio de Janeiro guardava ainda fortes características coloniais, muito evidentes no aspecto austero de seu casario urbano com seus cunhais em madeira aparente e telhados com generosos beirais lançando as águas da chuva diretamente sobre as ruas lamacentas. A presença muito viva da floresta luxuriante na paisagem urbana e o comércio muito diretamente fundamentado na produção agrícola local deixavam claro tratar-se de uma cidade despertando-se, ainda sonolenta, no leito de uma periferia rural preguiçosa. Sociedade que, sobretudo, se mostrava já dividida de forma desequilibrada entre uma elite branca abastada e minoritária, em geral portugueses ocupando-se do Estado Burocrático - magistrados, políticos, militares e clérigos -, em oposição a uma maioria negra, aproximadamente três quintos 


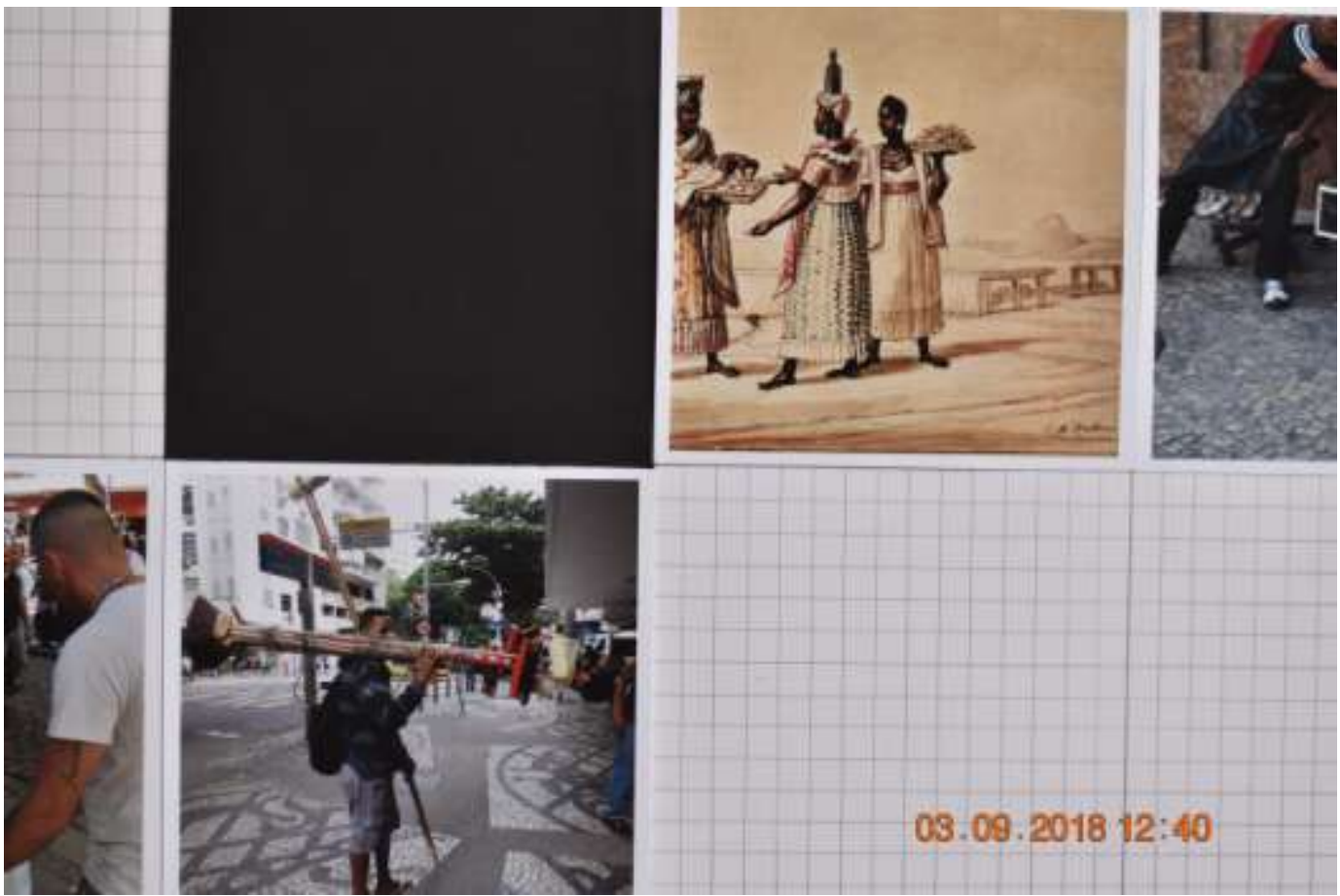

Fig. 2 - Luciano Vinhosa, Histórias cruzadas (detalhe), 2018

montagem / colagem/ desenho

Poiésis, Niterói, v. 19, n. 31, jan./jun. 2018. 
da população, de escravos urbanos de variados serviços ou trabalhando em chácaras, quintas, estâncias, roças e engenhos da periferia e recôncavo da Guanabara.

A Corte Portuguesa, refugiada das invasões napoleônicas, havia se exilado e se instalado voluntariamente no país em 1808, fundando aqui, em 16 de dezembro de 1815, o Reino Unido de Portugal, Brasil e Algarves. ${ }^{1}$ Já em 1816, por iniciativa do Conde da Barca, o monarca D. João VI viabilizou a vinda de um grupo de franceses, entre artistas, engenheiros e mestres de ofício, com fins a introduzir a capital do tosco império aos princípios balizares do mundo civilizado por meio do ensino acadêmico. Todos os esforços do monarca precipitaram-se na instauração de uma nova ordem cultural com a iniciação aos estudos das ciências e das Belas Artes, trazendo aos trópicos os brios de uma corte européia. 0 marco simbólico do processo foi a fundação, em 12 de agosto de 1826, da Escola de Ciências, Artes e Ofícios, que mais tarde deu origem a Academia Imperial de Belas Artes. Esta colônia de estrangeiros ficou conhecida historicamente como sendo a Missão Artística Francesa no Rio de Janeiro. ${ }^{2}$

Jean-Baptista Debret, artista integrante da Missão, além de outros encargos oficiais, ocupou-se por conta própria de documentar em desenhos, aquarelas, gravuras e relatos de observação direta, o cotidiano de cidade. Mais tarde, esse rico material, levado junto com ele para seu país, deu origem a uma publicação em três volumes, formato álbum, de Viagem pitoresca e histórica ao Brasil que apareceu na França ainda no século XIX. Em 1940, por iniciativa do industrial, mecenas e colecionador de arte brasileiro Raymundo Ottoni de Castro Maya, os originais de Debret foram repatriados, dando origem, em 1949, a uma edição nacional. ${ }^{3}$

Da vida das ruas no início do século XIX, o que se ressalta de seus registros é sem dúvida o burburinho da turba urbana, toda composta por escravos, negras e negros de aluguel ou de ganho que se dedicavam à venda de todo tipo de produtos culinários, de utensílios domésticos e de pequenos serviços prestados, a fim de avolumarem as rendas de seus proprietários, novos capitalistas urbanos. Uma população marginal, mas exposta à vida pública, enquanto os brancos se protegiam do sol refugiados em suas vivendas e casas de 
comércio. ${ }^{4}$ Quando apareciam em público, as mulheres mostravam-se parcialmente nas janelas, ao abrigo de suas gelosias, de onde podiam comprar com segurança algum produto oferecido pelos negros. (Fig. 3)

Naquela época, o mapa físico estava concentrado entre os morros do Castelo, assentamento primeiro da cidade, os de Santo Antônio, de São Bento e da Conceição. O perímetro urbano, seguindo o traçado natural da orla, não se estendia muito além do que hoje corresponde a zona portuária da cidade, de um lado, e aos limites da Glória, de outro, penetrando um pouco a Lapa, nas cercanias do que hoje são as ruas Riachuelo e Mem de Sá, não prosseguindo muito além de onde se encontra a Praça da Cruz Vermelha. Se estendia ainda ao longo de toda Rua Direita, hoje Primeiro de Março, se aprofundando até o Campo de Sant'Ana, a partir de onde as moradias urbanas se raleavam para dar lugar, pouco a pouco, às propriedades rurais. (ABREU, 1988, p. 35-37) O grosso dos negros vendedores e prestadores de serviços estava concentrado no Largo do Palácio, hoje Praça XV de Novembro, no entorno e muretas do chafariz do Mestre Valentim, entrada principal da cidade pelo mar, e nas proximidades da Alfândega, onde hoje encontra-se a Casa França Brasil, construção do arquiteto, igualmente francês e integrante da Missão, Grandjean de Montigny. Se distribuíam ainda pelos inúmeros pequenos cais ao longo das praias urbanas, pelas ruas mais habitadas e praças públicas mais frequentadas, sobretudo da região do Valongo, nas cercanias atuais da Praça Mauá e Praça Tiradentes, na oportunidade de encontrar seus clientes habituais. Como testemunha Debret em suas anotações:

Escolhi para cenário a praia do mercado de peixes, naturalmente muito movimentada por se encontrar, além do mais, nas proximidades da Alfândega. [...] São sete horas da manhã. As duas negras que aqui se acham acompanhadas à sombra de seus xales estendido sobre varas, servem (angu) no momento aos fregueses de maior apetite, isto é, os negros da alfândega. (DEBRET apud BAPTISTA, 2015, p. 26)

Anna Paula Baptista, seguindo as pistas deixadas por Debret, afirma ainda que os homens de classe média permaneciam no Largo do Palácio até às 19 horas, quando os sinos da Capela Imperial repicavam a ave-maria. O Largo era tomado, em seguida, por grupos de comerciantes, por capitães de navios mercantes e por oficiais de marinha estrangeiros

Poiésis, Niterói, v. 19, n. 31, jan./jun. 2018. 


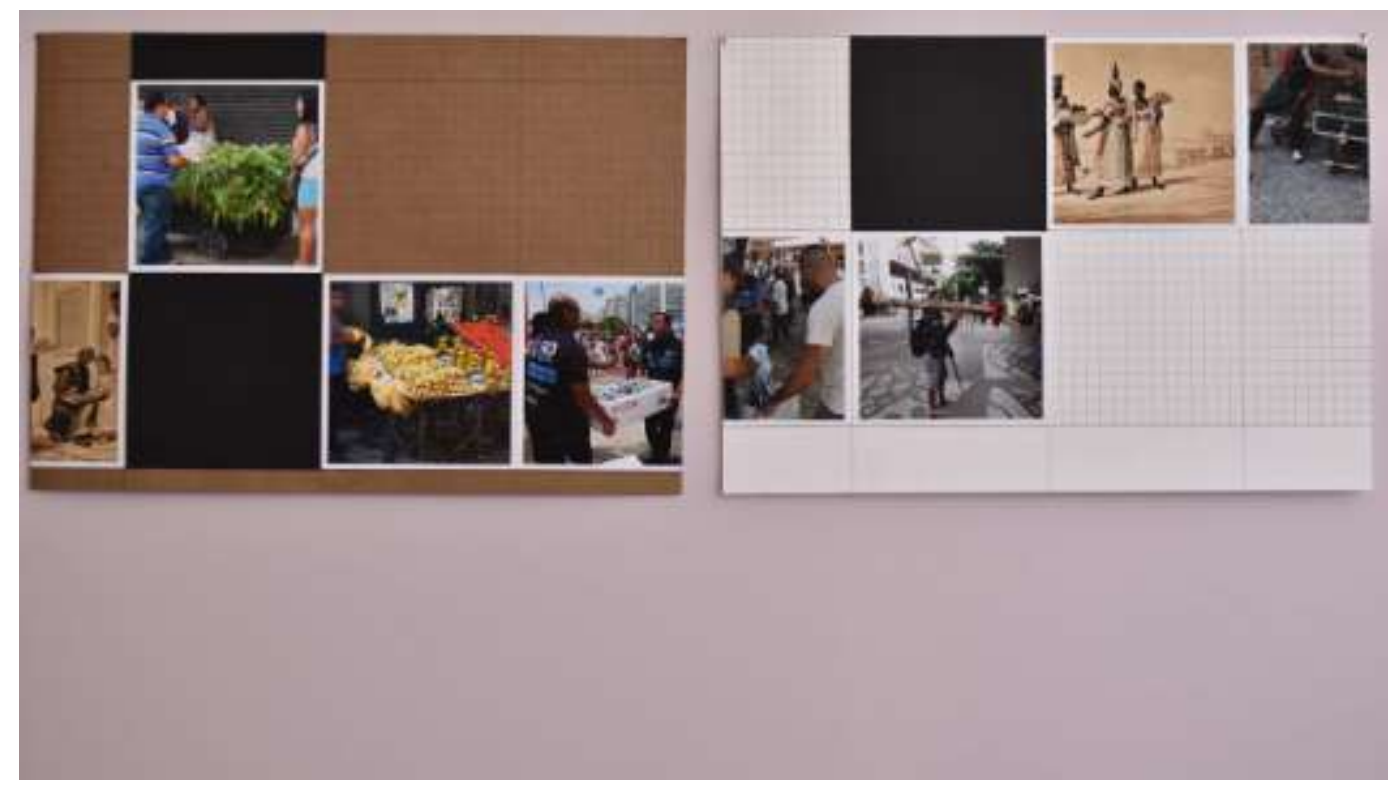

Fig. 3 - Luciano Vinhosa, Histórias cruzadas, 2018.

montagem / colagem/ desenho 
que desembarcavam para frequentar os cafés noturnos da Rua Direita. O movimento prosseguia animado até meia-noite, quando o Largo, finalmente, adormecia. (BAPTISTA, 2015 , p. 27) A presença dos negros vendilhões pode ser figurada por um mapa humano circunstancial, sobrepondo uma mancha negra temporária e movediça sobre o mapa físico da cidade, de maior extensão, concentrada no Largo do Palácio ou nas adjacências da Alfândega, das $7 \mathrm{~h}$ às $24 \mathrm{~h}$, dependendo do afluxo de transeuntes.

\section{Da alma encantadora das ruas}

No início do século XX, sob os auspícios da Velha República, os excedentes acumulados da produção cafeeira permitiu ao país, em particular à cidade do Rio de Janeiro, tomar a marcha da modernização industrial e intensificar o processo de urbanização que vinha sofrendo desde a chegada da Corte Portuguesa. O capital industrial e transnacional se fazia presente nas empreitadas urbanas da então Capital Federal, a maioria ligada ao setor dos serviços públicos, graças a concessões do Estado à companhias estrangeiras. (ABREU, 1988 , p. 35) São notáveis a implantação de um novo tipo de transporte de massas, o bonde elétrico, a instalação e exploração de redes de distribuição de gás, de iluminação elétrica, de distribuição de água e de saneamento básico, além da introdução do automóvel particular nas ruas da cidade. A expansão da infraestrutura teve como um dos objetivos agilizar a circulação e o escoamento de produtos e mercadorias, otimizando o fluxo das exportações/importações, abrindo o país ao mercado mundial. Com efeito, a edificação de novas instalações portuárias para atender as demandas do grande comércio internacional fez-se necessária. As remodelações no traçado urbano, com o ganho de novas áreas edificáveis conquistadas com o arrasamento de morros e consequentes aterros da orla da baia, mas também remarcável no alargamento das algumas ruas antigas e pela abertura de outras tantas novas na região central, foram concomitantes e complementares às novas atividades que a cidade viria assumir.

As reformas da época, conhecidas popularmente como o bota-abaixo, promovidas pelas ações conjuntas dos governos federal e municipal, reconhecidos nas figuras de Rodrigues

Poiésis, Niterói, v. 19, n. 31, jan./jun. 2018. 
Alves e de Pereira Passos respectivamente, transformaram a cidade em um imenso canteiro de obras. Se por um lado, conferiram ao Rio de Janeiro certo ar cosmopolita de uma capital européia, por outro contribuíram para engendrar uma sensível cisão entre pobres e ricos distribuídos entre as Zonas Norte e Sul, com toda franja de favelas que hoje abriga, e um centro cujas edificações são, em quase sua totalidade, destinadas às atividades comerciais e administrativas. Alguns exemplos emblemáticos foram as construções da Avenida Beira Mar, em terras conquistadas à Baia de Guanabara, indo da Glória até o final da Praia de Botafogo; sua extensão natural, a Avenida Central, hoje Rio Branco, cujas edificações suntuosas, destinadas ao comércio elegante, às atividades da alta cultura ${ }^{5}$ e a outras administrativas, deram à cidade ares de um bulevar parisiense. Juntas traçavam o caminho natural entre a Praça Mauá, porta de entrada para o país, também aberta na época, e a Zona Sul, que se estendia até Copacabana graças à perfuração do túnel do Leme. A abertura das Ruas Salvador de Sá e Mem de Sá foram possíveis a partir das terras obtidas com a conclusão da demolição do Morro do Senado e parte do de Santo Antônio. Além disso, foram realinhadas e alargadas as ruas Estácio de Sá, Frei Caneca, Assembléia, Uruguaiana, Carioca, Visconde do Rio Branco, Marechal Floriano, Visconde de Inhaúma, Treze de Maio, Acre, Camerino, Sete de Setembro, São José, Ramalho Urtigão e Mariz e Barros, esta última na Tijuca. Todas essas intervenções atingiram principalmente os bairros operários da região central, tendo como consequência não só o surgimento e o adensamento das favelas já existentes, mas também o deslocamento da população pobre para as zonas periféricas e distantes dos subúrbios por onde se estendia a malha ferroviária urbana.

João do Rio, cronista do início do século XX que testemunhou todo esse processo, não ficou indiferente às transformações. Frequentador das ruas do Rio de Janeiro e arguto observador, pôde remarcar que ao lado da modernização, no lugar de resolvê-las, as reformas acirraram as contradições sociais. Em suas crônicas reunidas no livro $A$ alma encantadora das ruas (ANTELO, 2005), deixa entender que, em meio à febre de modernização que sofreu a cidade, uma camada da sociedade excluída dos benefícios diretos, e que realmente não importava ao poder público, lutava heroicamente para sobreviver em meio 
às parcas oportunidades das ruas centrais. Descreve assim um dia febril, em 1904, quando o Rio começava a se modernizar:

Pelos bulevares sucessivos que vão dar no cais, a vida tumultuária da cidade vibrava num rumor de apoteose, e era ainda mais intensa, mais brutal, mais gritada, naquele trecho do Mercado, naquele pedaço de rampa, viscoso de imundícies e de vícios. (João do Rio apud ANTELLO, 2005, p. 87)

Entre as estratégias de sobrevivência e de resistência, estavam os inúmeros e pequenos "profissionais" clandestinos, vivendo de ganhos diários graças aos serviços prestados tanto aos pequenos quanto aos grandes capitalistas urbanos. Entre eles, o autor comenta sobre os trapeiros e catadores de papéis que recolhem das ruas os restos desses dejetos e os revendem às fábricas; sobre os catadores de sapatos velhos, contratados pelos remendões italianos que reformam e os revendem ao mercado. Das profissões bizarras, relata sobre a dos selistas que vivem de recolher das sarjetas os selos de maços vazios de cigarros, rótulos e anéis de charutos de marca consumidos, para revendê-los aos comerciantes de tabaco que falsificam as embalagens, fazendo uma marca inferior se passar por uma outra superior; sobre a dos caçadores de gato que vendem os animais abatidos aos restaurantes finos, que por sua vez os servem como se fossem lebres; sobre a dos ratoeiros que, beneficiando-se da onda da febre tifóide, caçavam ratos para vendê-los nos entrepostos da Diretoria de Saúde espalhados pela cidade.

Toda essa gente perambulava pelas ruas do centro da cidade - que incluía na época os bairros da região portuária, Gamboa e Saúde -, a Cidade Nova, o Morro do Castelo, e mesmo algumas áreas centrais da vizinha Niterói, em busca das oportunidades e das pequenas trapaças praticadas pelos comerciantes e industriais com quem eram coniventes. Um contingente urbano evidentemente pobre, sempre negligenciado e de certa forma invisível aos olhos da classe média abastada que frequentava os cafés e os magazines de artigos finos. Fato que o autor comenta com ironia e com uma ponta de amargura:

0 Rio pode conhecer muito bem a vida do burguês de Londres, as peças de Paris, a geografia da Mandchúria e o patriotismo do japonês. A apostar porém, que não conhece nem a sua própria planta, nem a

Poiésis, Niterói, v. 19, n. 31, jan./jun. 2018. 
vida de toda essa sociedade, de todos esses meios estranhos e exóticos, de todas as profissões que constituem o progresso, a dor, a miséria da vasta babel que se transforma. (João do Rio apud ANTELLO, 2005, p. 97)

A modernização dramática pela qual passava a cidade, e que a transformou em MaraviIhosa, acentuou as desigualdades sociais que só fez aprofundar-se com os planos subsequentes de ordenação urbana propostos por especialistas estrangeiros na primeira e no início da segunda metade do século XX. Desses, temos o Plano Agache ${ }^{6}$ do final dos anos vinte e o Doxiadis ${ }^{7}$, publicado em 1965, elaborados respectivamente por um urbanista francês e o outro por um grego. Embora implantados parcialmente, deixaram marcas significativas no tecido físico tanto como no social, contribuindo com a fisionomia de desigualdade social que cidade hoje ostenta. (Fig. 4)

O primeiro ocupou-se sobretudo de propor em 1921 um uso para a Esplanada do Castelo, extensão de terreno conquistada com o arrasamento do morro de mesmo nome e onde nasceu a cidade. A população pobre retirada do primeiro núcleo habitacional do Rio de Janeiro se viu obrigada a se acomodar como pôde nas favelas das imediações centrais e nos subúrbios cariocas em formação. O plano de remodelação e de embelezamento da cidade proposto por Agache criava no local um vasto quarteirão administrativo organizado desde uma grande praça chamada por ele de "Entrada do Brasil". Nunca foi implantado em sua íntegra, mas algumas tipologias de edificação e de uso do solo propostas pelo urbanista marcaram e transformaram definitivamente esta região. Os prédios atuais dos ministérios públicos do Trabalho e da Fazenda em estilo art déco; as passagens públicas existentes nos interiores dos blocos comerciais, compactos que ocupam toda extensão de alguns quarteirões no Castelo; a preservação do núcleo histórico da cidade compreendido entre a rua da Carioca e a avenida Presidente Vargas, com suas ruas para pedestres (região da Saara); a tipologia dos prédios em pilotis projetados sobre as calçadas que hoje vemos em parte da mesma avenida, são todos exemplos de suas proposições. Todo esse setor da cidade se tornou exclusivamente administrativo, comercial ou de serviços. Os edificações antigas, de uso residencial, que sobreviveram aquartelaram-se em torno da região portuária, nos bairros da Saúde, Santo Cristo, Gamboa e imediações da Praça Mauá, des- 


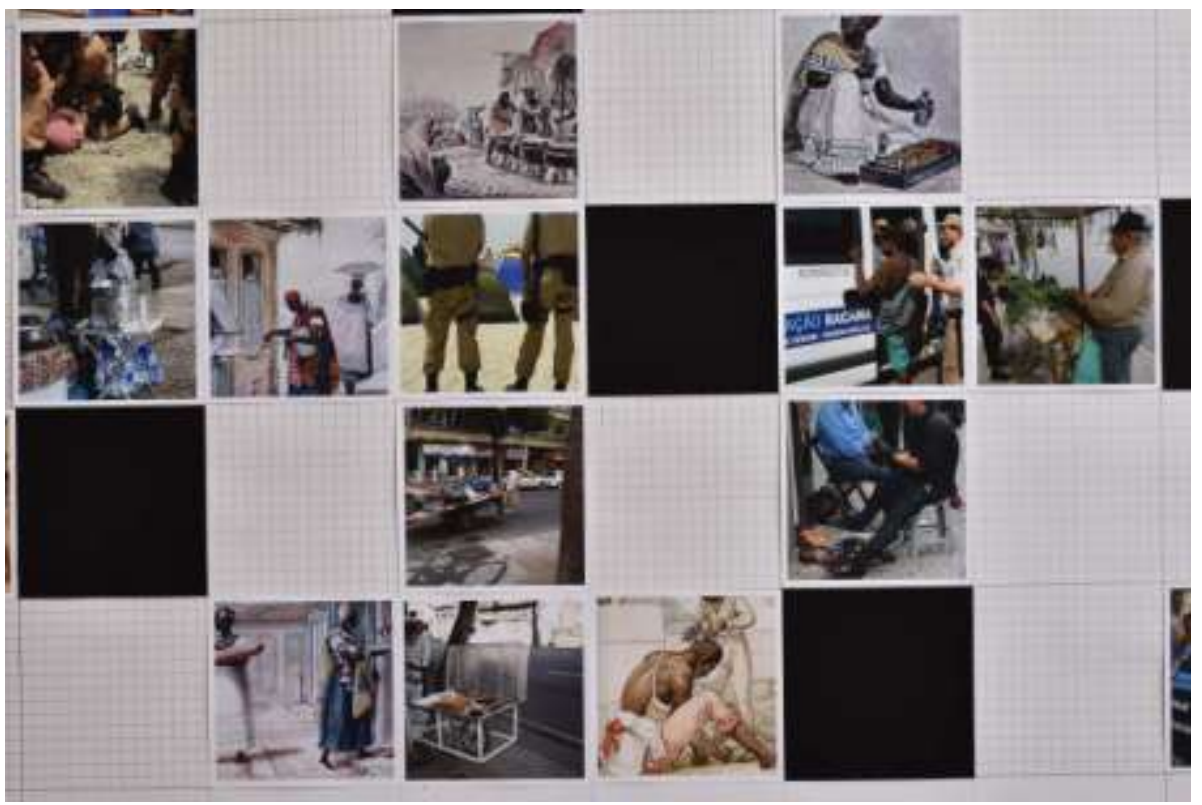

Fig. 4 - Luciano Vinhosa, Histórias cruzadas, 2018.

montagem / colagem/ desenho

Poiésis, Niterói, v. 19, n. 31, jan./jun. 2018. 
de sempre lugar de pobres, de estivadores e de prostituição. Hoje, com o projeto Porto Maravilha e a exemplo do que ocorreu no passado, esta região vem sofrendo profundas mudanças com as intervenções protagonizadas pelo capital privado, financiador dos investimentos imobiliários do setor hoteleiro e do financeiro, e pelo poder público, provedor de melhorias na infraestrutura. A região corre sérios riscos de passar pelo mesmo processo de gentrificação pelo qual passaram outras regiões centrais.

O segundo plano, também conhecido como policromático, foi pensado exclusivamente para o automóvel a fim de agilizar a circulação, favorecendo a entrada e a saída de veículos na cidade. Propôs a criação das vias expressas conhecidas tecnicamente como Linhas Lilás, Amarela, Vermelha, Verde, Azul, Marrom. A implementação parcial ou integral de algumas delas ao longo dos cinquenta últimos anos contribuiu para destroçar áreas habitacionais, antes organicamente integradas ao tecido urbano, como as que sobraram hoje dos bairros, por exemplo, do Catumbi, do Estácio e de São Cristovão: fragmentos deteriorados do tecido urbano, cortados por viadutos e pistas de alta velocidade, ocupados por uma população pobre e resistente.

\section{O Rio de Janeiro e suas camadas sobrepostas de tempos e espaços}

O espaço global está organizado, segundo Santos (2013), a partir de dois vetores, o vertical e o horizontal que, combinados, garantiriam o controle das forças hegemônicas do capital internacional. Eles são assim definidos pelo autor:

De um lado, há espaços contínuos, formados de pontos que se agregam sem descontinuidade, como na definição tradicional de região. São as horizontalidades De outro, há pontos no espaço que, separados uns dos outros, asseguram o funcionamento global da sociedade e da economia. São as veticalicades (SANTOS, 2013, p. 88)

As horizontalidades trabalham no nível do solo e religam as áreas de produção: a agricultura, sistemas de transportes campo-cidade por onde escoam as mercadorias e conectam a rede regional das cidades, suas trocas comerciais e pontos de escoamento de produtos 
para outras regiões do globo. As verticalidades, agindo no plano abstrato do mercado e do consumo mundial, através de objetos técnicos avançados, organizam o sistema estabelecendo as regras gerais de mercado, seus fluxos e afluxos de mercadorias, tudo a serviço das forças hegemônicas do capital internacional.

No entanto, é na grande cidade que esses dois fluxos se encontram e se chocam, levando o sistema como um todo ao estresse. A racionalidade e o controle promovidos pela verticalidade estão ali em risco de serem minados pelas horizontalidades, justamente porque esta traz em si contradições inerentes às diferentes espacialidades e temporalidades que residem no tecido urbano. Contradições que, inevitavelmente, criam no sistema certas fissuras, como observa Santos (2013):

Nas áreas de agricultura moderna, as cidades são o ponto de interseção entre verticalidades e horizontalidades. As verticalidades são vetores de uma racionalidade superior e de seu discurso pragmático, criando o cotidiano obediente. As horizontalidades são tanto o lugar da finalidade imposta de fora, de longe e de cima, quanto 0 da contra-finalidade, localmente gerada, o teatro de um cotidiano conforme, mas não obrigatoriamente conformista, e simultaneamente o lugar da cegueira e da descoberta, da complacência e da revolta.

[...] Nestas (nas cidades), os capitais hegemônicos e as práticas hegemônicas, fundados na racionalidade, têm mais dificuldade de se difundir, já que as frações mais antiga do meio ambiente construído não são funcionais para a operação dos capitais novos.

[...] Isso se deve exatamente ao fato de que a paisagem urbana reúne e associa pedaços de tempo materializados de forma diversa e, desse modo, autoriza comportamentos econômicos e sociais diversos. (SANTOS, 2013, p. 89-91)

O acesso desigual aos objetos técnicos de última geração faz com que certas zonas da cidade não sejam cooptadas pela luminescência do sistema. Protegidas de sua eficácia, graças à sua opacidade, elas escapam aos fluxos de suas velocidades e tornam-se zonas de exceções que não interessam nem ao capital nem ao puder público, que agem em con-

Poiésis, Niterói, v. 19, n. 31, jan./jun. 2018. 
junto e solidariamente. Os cidadãos negligenciados que habitam esses lugares esquecidos, ocupando um espaço diferenciado, vivem também em uma outra temporalidade que, paradoxalmente, os favorece. É um tempo lento assimilado em seus corpos e no anacronismo do espaço obsoleto. Através dos fluxos horizontais morosos que o lugar deteriorado propicia, têm o tempo necessário para estabelecer elos de sociabilidade mais efetivos, permeados pelas trocas afetivas, desenvolvendo táticas de resistência e dispositivos criativos de sobrevivência.

Os vendedores e prestadores de serviço ambulantes que povoam as ruas do Rio de Janeiro nos dias de hoje, quase todos pobres e negros como os escravos de outrora retratados por Debret, vivendo nas franjas do sistema e beneficiados pelo tempo lento, podem tirar proveito da situação e garantir uma sobrevida. Levando suas mercadorias e serviços especializados às ruas dos bairros, estão prontos para atender à demanda de última hora: reparar cano que estourou, arrematar uma parede, consertar um geladeira, vender um biscoito, um pedaço de bolo, um acarajé na hora da fome. Sua presença nas ruas, além do colorido habitual, aumenta a sensação de segurança. Não raro, tornam-se conhecidos por suas habilidades e competências, reforçando a rede de vizinhança e de confiabilidade mútua dos moradores. (Fig. 5, 6 e 7)

\section{Por uma outra cartografia}

Os vendedores e prestadores de serviços ambulantes - vassoureiros, quituteiros, sapateiros, fruteiros, tapioqueiros, biscoiteiros, empalhadores, bombeiros, engraxates, burrossem-rabos, herboristas, entre outros -, muitas das profissões de rua do tempo de Debret, ainda podem ser vistas em quase todas as partes de quase todos os bairros do Rio de Janeiro. Oportunistas que são, os vendilhões concentram suas atividades sobretudo nos entroncamentos de fluxos de pedestres, onde a turba humana se avoluma. Montam seus pequenos negócios e oferecem seus serviços próximos a entradas das estações de metrô, nos pontos finais de ônibus urbanos e, nas ocasiões de retenção do tráfego, nos engarrafamentos intermináveis que acometem a cidade. Todos pobres e quase todos negros, têm uma clientela em sua maioria de pobres também. Como tática para escapar da guar- 

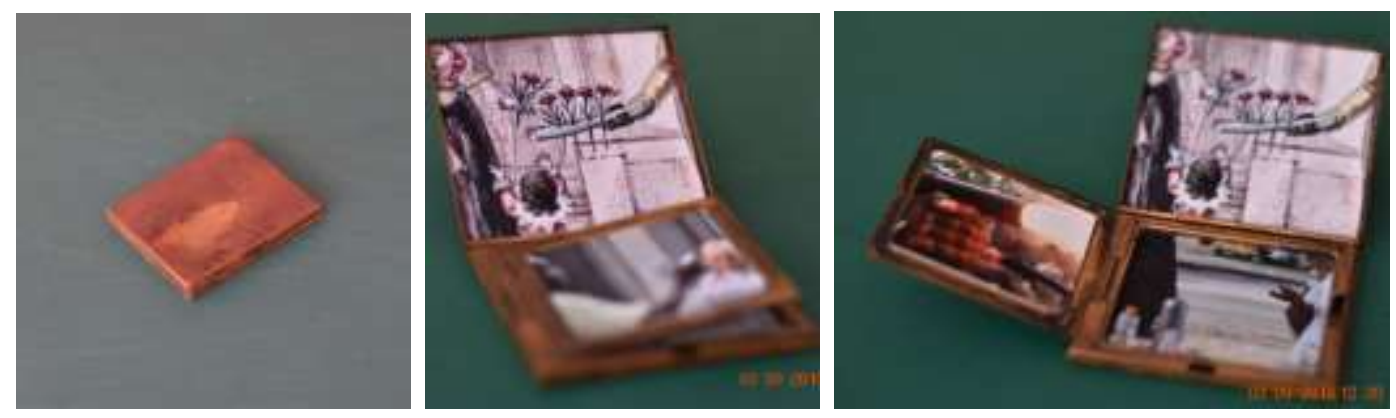

Fig. 5, 6, 7 - Luciano Vinhosa, Tempos dobrados, 2018.

montagem em caixas de metal

Poiésis, Niterói, v. 19, n. 31, jan./jun. 2018. 
da municipal, que Ihes confisca as mercadorias, desenvolveram seus displays de vendas sobre rodas, de modo que quase sempre estão em circulação. Esta tática lhes permite também aumentar a abrangência da área de atuação, deslocando-se para os picos de aglomerações oportunas na ocasião, por exemplo, de uma manifestação pública ou de evento artísticos. Não raro, seus veículos são ornados de forma original, de modo a chamar a atenção para seus produtos e a atrair a simpatia do cliente.

O centro da cidade, como nos tempos de antão, ainda é a região em que se concentram em grande escala. Da antiga Praça do Mercado e do Palácio, se deslocaram hoje para o Largo da Carioca, dando seguimento de suas vendas ambulantes pelas rua Uruguaiana e avenida Presidente Vargas, ramificando-se nas imediações do Largo de São Francisco e da rua da Carioca, onde hoje se aglomera grande parte dos escritórios e do comércio da cidade. Ocupam esta região de segundas às sextas-feiras, de 8:00 às 20:00 horas, quando o movimento de fregueses cai sensivelmente. No final de semana desaparecem e as ruas do centro tornam-se desertas e ameaçadoras, enquanto a cara da cidade volta a ser aquela, despovoada e fria, dos mapas oficiais.

Se no centro da cidade o grosso das atividades de ganho está concentrada na venda de pequenos gêneros alimentícios, nos bairros residenciais, por onde caminho, no entorno do Flamengo, do Catete e da Glória, os serviços são mais variados em produtos de utilidade doméstica: vassoureiros, fruteiros, empalhadores e sapateiros, por exemplo.

Essa cidade de ambulantes, muito exposta aos sentidos de quem caminha, desenha temporariamente sobre a oficial uma outra oficiosa, alegre, muito colorida e gritada nos dias de sol. Faz emergir, em oposição à cidade de sobrevoo mostrada nas cartas oficiais, uma outra: rasteira, efêmera e sazonal, praticada apenas no nível do solo por seus usuários. 


\section{Notas}

\footnotetext{
${ }^{1}$ http://pt.wikipedia.org/wiki/Reino_Unido_de_Portugal,_Brasil_e_Algarves. Consulta realizada no dia 1/5/2015.

2 http://pt.wikipedia.org/wiki/Academia_Imperial_de_Belas_Artes. Consulta realizada no dia 1/5/2015.

3 DEBRET, Jean-Baptiste. Viagem pitoresca e histórica ao Brasil. São Paulo: Livraria Martins, 1949.

${ }^{4}$ As ruas dessa época, dando crédito aos relatos de Debret, eram freqüentadas, em geral, por escravos e homens brancos. As mulheres brancas, em suas raras aparições públicas, são vistas em interior de liteiras, em procissões ou nas portadas das igrejas católicas, entrando ou saindo das missas.

5 Entre os quais o Teatro Municipal, a Biblioteca Nacional e o Museu Nacional de Belas Artes. Este último, na verdade, foi criado em 1937, ocupando o mesmo prédio em que se encontra hoje, mas dividindo suas dependências com Escola Nacional de Belas Artes até 1975, quando esta foi transferida para a Cidade Universitária na Itha do Fundão.

6 Plano Agache - denominação popular do plano de remodelação urbana da cidade do Rio de Janeiro elaborado no final da década de 1920, por Alfred Agache, por solicitação do então prefeito da cidade, Antônio Prado Júnior. http://pt.wikipedia.org/wiki/Plano_Agache; consulta no dia 3/5/2015.

${ }^{7}$ Plano Doxiadis - também conhecido como Plano Policromático, foi publicado em 1965 e concebido pelo arquiteto e urbanista grego Constantino Doxiádis, sob encomenda do então governador do estado da Guanabara, Carlos Lacerda (1960-1965). http://pt.wikipedia.org/wiki/Plano_Doxiadis; consulta no dia 3/5/2015.
}

\section{Referências}

ABREU, Mauricio de. Evolução urbana do Rio de Janeiro. Rio de Janeiro: Zahar, 1988.

ANTELO, Raul (Org.). João do Rio, a alma encantadora das ruas. São Paulo: Cia. das Letras, 2005.

BAPTISTA, Anna Paula. O Rio de Janeiro de Debret: coleção Castro Maya. (catálogo de exposição; curadoria de Anna Paula Baptista). Rio de Janeiro: Centro Cultural dos Correios, 2015.

SANTOS, Milton. Técnica, espaço, tempo. São Paulo: EDUSP, 2013.

Poiésis, Niterói, v. 19, n. 31, jan./jun. 2018. 